\title{
Public Health Genomics knowledge and attitudes: A survey of public health educators in the United States
}

Lei-Shih Chen, $\mathrm{PhD}, \mathrm{CHES}^{1}$, and Patricia Goodson, $\mathrm{PhD}{ }^{2}$

\begin{abstract}
Purpose: This study assessed U.S. public health educators' attitudes toward genomic competencies, their awareness of efforts in the health promotion field to promote/incorporate genomics, and their basic \& applied genomic knowledge. Methods: A total of 1607 public health educators, nationwide, responded to a web-based survey. Results: The sample comprised predominantly white (76.8\%) female (83.9\%) participants, with an average age of 40.1 years and 11.2 years of practice in public health education/promotion. Generally, participants had negative attitudes toward genomic competencies, low awareness, and deficient genomic knowledge. Although various socioeconomic characteristics (e.g., ethnicity, gender, and educational level) correlated with participants' attitudes, awareness, and genomic knowledge, training in genetics/genomics or public health genomics also exhibited a positive association. After we controlled for socioeconomic factors, awareness, training, and genomic knowledge remained significantly associated with respondents' attitudes toward genomic competencies. Conclusion: Although this sample of public health educators had unfavorable attitudes and limited genomic knowledge, training seems to affect these variables. Thus, relevant training for this group of health professionals should be developed and advocated. Continuing education tools, focusing on public health genomics content, might be a venue for delivery of information and the development of favorable professional attitudes. Genet Med 2007:9(8):496-503.
\end{abstract}

Key Words: public health genomics, public health educators, knowledge, attitudes

According to the Centers for Disease Control and Prevention (CDC), Public Health Genomics (PHG) consists of "the study and application of knowledge about the elements of the human genome and their functions, including interactions with the environment, in relation to health and disease in populations." Because of its multidisciplinary nature, collaboration among various fields is required to advance PHG. These fields include molecular epidemiology, pathobiology, bioinformatics, pharmacogenetics, nutrition, health services, public policy, bioethics, law, health promotion, and health education. Applying genomics information and technologies to improve population health and prevent diseases represents PHG's ultimate goal. ${ }^{1,2}$

As one of its team players, public health educators have a unique and critical role in PHG. Because public health educators bridge the gap between the health care system and lay public communities, they can reflect communities' concerns to health care professionals and policy makers, and help health professionals communicate with community groups and individuals appropri-

From the ${ }^{1}$ Department of Public Health, University of North Florida, Jacksonville, Florida; and ${ }^{2}$ Department of Health and Kinesiology, Texas A\&M University, College Station, Texas. Disclosure: The authors declare no conflict of interest.

Lei-Shih Chen, PhD, CHES, Department of Public Health, University of North Florida, 4567 St. Johns Bluff Road, Jacksonville, FL 32224.E-mail: lace@hlkn.tamu.edu.

Submitted for publication April 3, 2007.

Accepted for publication May 18, 2007.

DOI: 10.1097/GIM.0b013e31812e95b5 ately regarding genomic information and technologies. ${ }^{3}$ Moreover, research and practice carried out by public health educators can also increase lay communities' genetic/genomic knowledge, determine the impact of available genomic technologies on the public's health and well-being, affect the lay public's satisfaction with genetic/genomic services, and facilitate lifestyle changes by using family history and genetic test results. ${ }^{4,5}$

Several professional organizations have advocated the need for public health educators to develop their genomic competencies to conduct genomics-related health promotion and disease prevention. For example, the Institute of Medicine recommends genomics as one of eight new content areas to be covered by every school of public health. Public health schools and programs should educate their students to recognize the importance of genomics, encompass essential understanding of genomics, and consider the ethical, legal, and social implications of genomics. ${ }^{6}$ The CDC also developed seven genomic competencies for public health educators. These genomic competencies "were developed as a tool for public health programs and schools of public health to incorporate genomics into existing competencies and program training goals." ${ }^{\prime \prime}$ In addition, the National Coalition for Health Professional Education in Genetics (NCHPEG) established core competencies in genetics for health professionals. These include 17 knowledge competencies, 17 skills competencies, and 10 attitude competencies. ${ }^{8}$

To date, however, no studies have examined public health educators' awareness of such professional development efforts in the health promotion field or their attitudes toward the 
CDC-proposed genomic competencies (developed specifically for this group of professionals). Also, scholars and practitioners know little about public health educators' knowledge of genomics, because the curricula of most health education programs do not include course work in that topic area. As practicing genomics competencies, therefore, constitute a relatively new concept for public health educators (i.e., an innovation), we adopted Rogers' Diffusion of Innovations Theory ${ }^{9}$ as a framework for this study. According to this theory, individuals' knowledge can impact their attitudes, which, in turn, influence their decision to adopt and implement an innovation. In addition, the theory also postulates that socioeconomic characteristics are associated with individuals' knowledge and attitudes. ${ }^{9}$

We conducted this study specifically to assess (1) U.S. public health educators' attitudes toward the CDC-proposed genomic competencies; (2) these public health educators' awareness of efforts in the health promotion field to promote/incorporate genomics; (3) their knowledge of basic \& applied genomic principles; (4) the associations among select socioeconomic characteristics and public health educators' attitudes, awareness, and basic \& applied genomic knowledge; and (5) the relationship among attitudes, awareness, and basic \& applied genomic knowledge.

\section{MATERIALS AND METHODS}

\section{Instrument}

For survey of public health educators nationwide, we developed a web-based instrument entitled "Health Promotion and Genetics/Genomics Survey (HPGS).” We developed the tool with the assistance of Zoomerang (a commercial web-based survey engine) and conducted cognitive and retrospective interviews to ensure the measures elicited valid and reliable data. ${ }^{10}$ One geneticist and three faculty members in health education/health behavior at two universities assessed the measures' content validity. To help refine and test the survey procedures, we conducted a pilot test, distributing the instrument to a random sample of 385 public health educators (adjusted response rate $=21.5 \%$ ). Findings from the pilot study informed minor changes in the final version of the instrument and survey procedures.

The final version of the HPGS instrument asked participants about their socioeconomic characteristics, including their age, gender, ethnicity (self-reported measure using white, Black/ African American, Asian/Pacific Islander, Alaskan Native/ American [Native] Indian, Hispanic/Latino, and other as nonorthogonal categories), religious preference, education level, work settings, years of practice, training in PHG, and their Health Education Specialist Certified (CHES) status. Subsequently, 14 questions focused on their beliefs $(n=7)$ and values $(n=7)$ related to the seven genomic competencies proposed by the CDC for health educators (and reworded for this study; see Table 1). In the last two sections of the survey, as listed in Table 2, five items asked if public health educators were familiar with efforts made in the health promotion field to promote/adopt PHG (responses were given in a 5-point Likert scale, ranging from "not familiar at all" to "completely familiar"), and six multiple-choice questions, modified from the instrument developed by Bankhead et al. ${ }^{11}$ and Henneman

\section{Table 1}

Percentage distribution of public health educators' responses to questions regarding their attitudes toward the modified Centers for Disease Control and Prevention genomic competencies $(N=1607)$

\begin{tabular}{|c|c|c|c|c|}
\hline \multirow[b]{3}{*}{ Health educators' genomic competencies } & \multicolumn{4}{|c|}{ Attitudes toward Public Health Genomics } \\
\hline & \multicolumn{2}{|c|}{ Beliefs } & \multicolumn{2}{|c|}{ Values } \\
\hline & Agree (\%) & Disagree (\%) & Important (\%) & Not important (\%) \\
\hline $\begin{array}{l}\text { Translating complex genomic information for use in } \\
\text { community-based health education programs }\end{array}$ & $87.8 \%$ & $12.2 \%$ & $48.9 \%$ & $51.1 \%$ \\
\hline $\begin{array}{l}\text { Facilitating genomic education for agency staff, } \\
\text { administrators, volunteers, community groups, } \\
\text { and other interested personnel }\end{array}$ & $87.6 \%$ & $12.4 \%$ & $45.5 \%$ & $54.6 \%$ \\
\hline $\begin{array}{l}\text { Developing a plan for incorporating genomics into } \\
\text { health education services by working with } \\
\text { community organizations, genomic experts, and } \\
\text { other stakeholders }\end{array}$ & $88.6 \%$ & $11.4 \%$ & $47.4 \%$ & $52.6 \%$ \\
\hline $\begin{array}{l}\text { Conducting a needs assessment for community-based } \\
\text { genomic education programs }\end{array}$ & $90.8 \%$ & $9.1 \%$ & $52.0 \%$ & $48.0 \%$ \\
\hline $\begin{array}{l}\text { Advocating for community-based genomic education } \\
\text { programs }\end{array}$ & $86.6 \%$ & $13.3 \%$ & $49.5 \%$ & $50.5 \%$ \\
\hline $\begin{array}{l}\text { Integrating genomic components into community- } \\
\text { based genomic education programs }\end{array}$ & $88.6 \%$ & $11.4 \%$ & $52.3 \%$ & $47.8 \%$ \\
\hline $\begin{array}{l}\text { Evaluating the effectiveness of community-based } \\
\text { genomic education programs }\end{array}$ & $89.9 \%$ & $10.1 \%$ & $49.4 \%$ & $50.5 \%$ \\
\hline
\end{tabular}


Table 2

Percentage distribution of public health educators' responses to questions regarding their awareness of efforts in the health promotion field to promote/incorporate Public Health Genomics (awareness)

\begin{tabular}{|c|c|c|c|}
\hline Please rate your familiarity with... & Familiar & $\begin{array}{c}\text { Not } \\
\text { familiar }\end{array}$ & Neutral \\
\hline $\begin{array}{l}\text { "Genetics" has been added to phase } 2 \\
\text { (Epidemiological Assessment) of } \\
\text { the PRECEDE-PROCEED Model }\end{array}$ & 26.4 & 61.1 & 12.5 \\
\hline $\begin{array}{l}\text { The Institute of Medicine has } \\
\text { recommended genomics as one of } \\
\text { eight new content areas for public } \\
\text { health education programs }\end{array}$ & 5.7 & 84.8 & 9.5 \\
\hline $\begin{array}{l}\text { The CDC has recommended seven } \\
\text { genomic competencies for health } \\
\text { educators }\end{array}$ & 3.9 & 87.5 & 8.6 \\
\hline $\begin{array}{l}\text { The NCHPEG has established the } \\
\text { core competencies in genetics for } \\
\text { health professionals }\end{array}$ & 3.5 & 89.6 & 6.9 \\
\hline $\begin{array}{l}\text { The CDC and three universities }{ }^{a} \\
\text { developed the web-based training } \\
\text { tool, E-Facts on Public Health } \\
\text { Genomics (formerly Genomics for } \\
\text { Public Health Practitioners) }\end{array}$ & 3.4 & 90.6 & 6.0 \\
\hline
\end{tabular}

NCHPEG, National Coalition for Health Professional Education in Genetics; CDC, Centers for Disease Control and Prevention.

${ }^{a}$ University of Michigan, University of North Carolina, and University of Washington.

et al., ${ }^{12}$ assessed respondents' knowledge related to basic and applied genomics.

To reduce the phenomenon of social desirability in respondents' answers, we did not inform them that the genomic competencies listed in the beliefs and values questions were proposed by the CDC. Furthermore, we positioned the knowledge and awareness items at the end of the survey to prevent biasing respondents' beliefs and values related to the proposed competencies. Such placement helped avoid respondents' potential feelings of ineptness or ignorance, which might have precluded their completing the entire survey. It took participants 15 to 20 minutes to complete the questionnaire. Participants could receive incentives for participating in the survey by entering a drawing for four $\$ 50$ money order certificates. To take advantage of the learning opportunity this survey represented, participants could access five PHG educational resources to learn more about PHG. The final version of the HPGS is available on request to the first author.

\section{Study sample}

We requested approval from five major public health education and health promotion organizations to access members' e-mails, and obtained permission from three organizations: the National Commission for Health Education Credentialing, Society for Public Health Education, and School Health Education and Services Section of the American Public Health Association. Furthermore, the Health Education E-mail Directory, a major health education electronic communication listserv comprising most members of the American Associa- tion of Health Education, granted us permission to contact its members through e-mail. In total, we collected 9391 e-mail addresses.

\section{Procedures}

All study procedures were approved by the Institutional Review Board of Texas A\&M University. As with most web-based surveys, participation was construed as informed consent: Respondents could only access the survey questions after reading an instruction sheet with information regarding the voluntary and anonymous nature of the study, and clicking on the link to proceed with the questions.

Unlike many other professional groups, an exhaustive listing of all practicing public health educators nationwide is nonexistent. Given such limitation, our study's design focused on surveying all 9391 persons identified in the listings provided by the Society for Public Health Education, National Commission for Health Education Credentialing, School Health Education and Services Section of the American Public Health Association, and Health Education E-mail Directory. Everyone received three tailored e-mails (one notice and two follow-ups), containing the link to the HPGS and inviting his/her participation. In the personalized e-mails (sent by the first author), we mentioned our inclusion criteria: To be eligible to participate, respondents should self-identify as a health educator/ health promoter and currently work as a health educator/ health promoter.

Of the 9391 e-mail invitations sent, 1333 proved invalid (i.e., 1267 were undeliverable, duplicated, or incorrect; and 66 respondents informed us they did not meet our inclusion criteria). Among the remaining 8058 valid e-mails, 1862 public health educators completed the survey (adjusted response rate $=$ $23.1 \%)$. Because of the anonymity of the HPGS, we could not assess potential bias in the response rate by examining whether respondents differed from nonrespondents in any systematic manner.

\section{Statistical analyses}

We performed all statistical analyses of survey data using the Statistical Package for the Social Sciences version 14.0 (SPSS Inc., Chicago, IL). We also assessed the data for missingness and frequency distributions. Because $17 \%$ of the data for the attitudes scaled variable (developed by linearly combining scores on the beliefs and values questions) were missing, we imputed the mean for the overall attitude score to estimate missing values. ${ }^{13}$ Various multiple regression models assessed the associations among socioeconomic characteristics, attitudes, awareness, and basic \& applied genomic knowledge. Probabilities less than 0.05 were considered statistically significant, when testing null hypotheses.

We also tested the data's validity and reliability through exploratory factor analysis and Cronbach's alpha. The construct validity of the basic and applied knowledge data were also assessed through confirmatory factor analysis, with the assistance of Analysis of Moment Structures, version 7.0. Validity and reliability testing indicated the data were psychometrically 
sound ${ }^{14}$ (further details of psychometric testing are available from the first author).

\section{RESULTS}

\section{Socioeconomic characteristics of the sample}

From among the 1862 returned surveys, we eliminated from analysis those containing items exhibiting more than 50\% missing data; therefore, the final sample consisted of 1607 valid questionnaires. Participants' average age was 40.1 years (standard deviation $=12.0$ ), and the average years of practice in health education was 11.2 (standard deviation $=9.3$ ). Respondents were predominantly white $(76.8 \%)$, female $(83.9 \%)$, and CHES certified (81.1\%). Most identified themselves as Christian $(70.5 \%)$. Respondents were allowed to choose multiple work settings, thus $51.7 \%$ worked in a community setting, $44.4 \%$ worked in a college/university setting, $37.3 \%$ worked in a government setting, and $35.8 \%$ worked in a health care setting. The majority of respondents $(71.4 \%)$ had never received any training in genetics, genomics, or PHG, whereas $15.6 \%$ had taken courses and $13.1 \%$ had received other types of training in PHG (e.g., obtaining continuing education units, attending conferences, receiving job training, and conducting research).

\section{Attitudes toward genomic competencies}

Table 1 displays the frequency of respondents' agreement with each of the genomic competencies presented to them. Because our measure of attitudes comprised two dimensions (beliefs and values), respondents were first asked whether they agreed/disagreed with the seven statements related to specific genomic tasks (belief items). In general, most participants (88.6\%) strongly agreed/agreed with the genomic competencies being proposed for the public health education workforce. The highest frequency of agreement was found for the competency "conducting a needs assessment for community-based genomic education programs (90.8\%)," whereas "advocating for community-based genomic education programs" had the weakest endorsement $(86.6 \%)$.

Although the majority of respondents agreed with the proposed competencies, less than half of the sample (49.3\%) valued their practice. Forty-five percent recognized facilitation of genomic education for agency staff, administrators, volunteers, community groups, and other interested personnel as important, and $52.3 \%$ admitted integrating genomic components into community-based genomic education programs is a valuable task.

\section{Awareness of efforts in the health promotion field to promote/incorporate Public Health Genomics}

We also assessed whether participants knew about the efforts being made in the health promotion field to promote/ incorporate PHG (Table 2). Overall, the sample demonstrated little awareness of key events, or elements, related to PHG. Less than one third (26.4\%) was familiar with the fact that "Genetics" has been added to Phase 2 (Epidemiological Assessment) of the PRECEDE-PROCEED Model, a widely adopted health intervention planning model. This model describes specific stages for planning and evaluating population-based health programs. Each stage focuses on various administrative, policy, educational, ecological, epidemiologic, and social factors influencing health behaviors. ${ }^{15}$ Similarly, most were unaware that the Institute of Medicine has recommended genomics as one of eight new content areas for public health education programs (84.8\%). Most respondents lacked familiarity with the CDC's seven recommended genomic competencies for public health educators $(87.5 \%)$ and did not know that the NCHPEG has established core competencies in genetics for health professionals (89.6\%). Nearly the entire sample ignored the fact that the CDC, University of Michigan, University of North Carolina, and University of Washington have developed a web-based training tool, "E-Facts on Public Health Genomics," to train public health workers in PHG (90.6\%).

\section{Basic \& applied genomic knowledge}

Survey participants answered six multiple-choice items, developed to measure basic (three items) and applied genomic knowledge (three items). Each question comprised six response options, but only one was correct. On average, $51.1 \%$ of the answers to the six items regarding basic \& applied genomic knowledge were correct (equivalent to an " $\mathrm{F}$ " grade, in most university settings). Respondents exhibited higher scores for the applied genomic knowledge items than for the basic knowledge items. For instance, the majority of participants $(89.0 \%)$ answered correctly that "taking folic acid before and during the early stages of pregnancy could reduce a fetus' risk of neural tube defects (applied knowledge item)." Although most $(85.5 \%)$ knew that positive genetic testing results indicated a higher-than-average risk for a specific disorder (applied knowledge), approximately $70 \%$ did not recognize that genetic testing was used both to detect individuals' genotype (basic knowledge) and to calculate the offspring's chance of developing an autosomal recessive disorder if both parents are carriers (basic knowledge). Almost half stated they could not make appropriate public health recommendations based on the findings from their clients' family histories. The question regarding the Human Genome Project had the lowest correct response rate: Only one fifth of the respondents answered correctly that $99.9 \%$ of nucleotide bases were exactly the same in all people.

\section{Socioeconomic characteristics associated with attitudes, awareness, and basic \& applied genomic knowledge}

To assess whether select socioeconomic characteristics were associated with attitudes, awareness, and basic \& applied genomic knowledge in our sample, we ran a series of regression analyses. The analyses consisted of developing various regression models, beginning with a demographic-characteristicsonly model (i.e., age, gender, ethnicity) and systematically adding one or two related variables to the preceding models. Table 3 presents only the final model in each series, containing all variables, because these models comprise the maximum amount of 
Table 3

Multiple regression analyses of predictors of public health educators' attitudes toward genomic competencies, awareness of efforts in the health promotion field to promote/incorporate Public Health Genomics, and basic \& applied genomic knowledge

\begin{tabular}{|c|c|c|c|c|c|c|c|c|c|}
\hline \multirow[b]{2}{*}{ Predictors } & \multicolumn{3}{|c|}{$\begin{array}{c}\text { Model 1 } \\
\text { Attitudes } \\
\text { (adjusted } \mathrm{R}^{2}=0.11 \text { ) }\end{array}$} & \multicolumn{3}{|c|}{$\begin{array}{c}\text { Model } 2 \\
\text { Awareness } \\
\text { (adjusted } \mathrm{R}^{2}=0.05 \text { ) }\end{array}$} & \multicolumn{3}{|c|}{$\begin{array}{l}\text { Model } 3 \\
\text { Basic and applied knowledge } \\
\quad \text { (adjusted } \mathrm{R}^{2}=0.06 \text { ) }\end{array}$} \\
\hline & $\beta$ & SE & $P$ value & $\beta$ & SE & $P$ value & $\beta$ & SE & $P$ value \\
\hline Age & -0.002 & 0.064 & 0.952 & -0.049 & 0.013 & 0.227 & -0.019 & 0.005 & 0.645 \\
\hline \multicolumn{10}{|l|}{ Gender } \\
\hline Male/female & -0.012 & 1.418 & 0.672 & -0.064 & 0.278 & 0.020 & 0.080 & 0.103 & 0.004 \\
\hline \multicolumn{10}{|l|}{ Ethnicity } \\
\hline Nonwhite/white & -0.078 & 1.196 & 0.004 & -0.060 & 0.239 & 0.027 & 0.076 & 0.087 & 0.005 \\
\hline \multicolumn{10}{|l|}{ Religious preference } \\
\hline Non-Christian/Christian & -0.008 & 1.092 & 0.752 & 0.016 & 0.217 & 0.558 & -0.072 & 0.080 & 0.008 \\
\hline \multicolumn{10}{|l|}{ Degree } \\
\hline Bachelor's degree or less/Master's degree & -0.053 & 1.335 & 0.127 & -0.041 & 0.269 & 0.250 & 0.048 & 0.097 & 0.179 \\
\hline \multicolumn{10}{|l|}{ Degree } \\
\hline Bachelor's degree or less/Doctoral degree & -0.024 & 1.777 & 0.530 & 0.113 & 0.355 & 0.004 & 0.123 & 0.128 & 0.001 \\
\hline \multicolumn{10}{|l|}{ CHES certified } \\
\hline No/Yes & 0.050 & 2.969 & 0.528 & 0.177 & 0.583 & 0.025 & 0.142 & 0.215 & 0.076 \\
\hline \multicolumn{10}{|l|}{ Work setting } \\
\hline Non-health care setting/health care setting ${ }^{a}$ & 0.002 & 2.549 & 0.980 & -0.162 & 0.498 & 0.040 & -0.098 & 0.185 & 0.222 \\
\hline Years of professional practice & -0.042 & 0.084 & 0.303 & 0.037 & 0.017 & 0.381 & -0.092 & 0.006 & 0.026 \\
\hline \multicolumn{10}{|l|}{ Training in genetics/genomics or PHG } \\
\hline No training/took courses & 0.032 & 1.429 & 0.248 & 0.156 & 0.276 & 0.000 & 0.171 & 0.102 & 0.000 \\
\hline \multicolumn{10}{|l|}{ Training in genetics/genomics or PHG } \\
\hline No training/other training ${ }^{b}$ & 0.066 & 2.299 & 0.014 & 0.063 & 0.464 & 0.020 & 0.058 & 0.166 & 0.033 \\
\hline Awareness & 0.279 & 0.137 & 0.000 & - & - & - & - & - & - \\
\hline basic \& applied genomic knowledge & 0.071 & 0.380 & 0.010 & - & - & - & - & - & - \\
\hline
\end{tabular}

PHG, Public Health Genomics.

${ }^{a}$ Health care setting also included college/university health services setting.

${ }^{b}$ Other training included CE units, conferences, job training, research, and self-study.

statistical controlling. Testing of the data also indicated the absence of a multicollinearity problem for the models.

In Model 1, ethnicity (being nonwhite) and training in PHG were the only two socioeconomic factors positively and significantly associated with respondents' attitudes toward genomic competencies. Yet, their regression coefficients were small $(\beta=$ -0.078 for ethnicity and $\beta=0.066$ for training) and could, therefore, represent a spurious relationship.

Model 2 examined respondents' awareness of the efforts made in the health promotion field to promote/incorporate PHG. An overall awareness score was calculated by summing respondents' scores on five relevant items. Seven socioeconomic factors were significantly related to respondents' level of awareness in a positive direction: gender (male), ethnicity (nonwhite), doctoral degree, CHES certification, working in a non-health care setting, and taking courses related to genetics/genomics or other training related to PHG. Among these factors, the strongest predictor of aware- ness was whether respondents were certified as health education specialists $(\beta=0.177)$.

Model 3 assessed respondents' socioeconomic characteristics and their relationship with basic \& applied genomic knowledge. The basic \& applied genomic knowledge index was computed as the sum of respondents' answers to six knowledge items. Model 3 indicates that those who were male, white, and nonChristian; had a doctoral degree, fewer years of work in health education/promotion, and training in genetics/genomics scored higher in the basic and applied genomics items. Moreover, training had the strongest association with basic \& applied genomic knowledge $(\beta=0.171)$.

\section{Associations among attitudes, awareness, and basic \& applied genomic knowledge}

In Table 3, Model 1 also assessed whether both awareness and basic \& applied genomic knowledge were associated with 
respondents' attitudes toward genomic competencies, after controlling for the variance of the socioeconomic factors. Stronger awareness of efforts in the field to incorporate PHG was the strongest predictor $(\beta=0.279)$ of better attitudes toward PHG competencies.

\section{DISCUSSION}

Researchers have surveyed various health professionals' attitudes and/or knowledge regarding genetics/genomics. ${ }^{16-29}$ To the best of our knowledge, however, this is the first study assessing public health educators' attitudes, awareness, and genomic knowledge related to PHG. Because public health educators work directly with the lay public and within multidisciplinary professional teams, they play an important role in genomics by providing various types of educational and health promotion services to the public, and by working closely with other health care professionals to facilitate the public's informed decision-making to promote health literacy and help maintain healthy behavior. ${ }^{5,30}$ According to the Diffusion of Innovations Theory, ${ }^{9}$ the decision-making regarding adoption of any innovation develops over five phases, namely, knowing about the innovation and how to use it (phase 1), espousing positive attitudes about the innovation (phase 2), deciding to adopt the innovation (phase 3), implementing or using the innovation (phase 4), and seeking out reinforcements for the initial decision to adopt (phase 5). To better understand and use the talents of public health educators in multidisciplinary teams working with PHG, it is important to learn where these professionals currently stand in this decision-making process and which strategies might help foster efficient adoption. Our study takes a first step toward such understanding, because it examines health educators' knowledge and attitudes toward PHG.

Findings from this study's sample indicate a health education workforce that seems ambivalent regarding the need to incorporate genomic competencies into practice: Although the majority agree with the CDC-proposed competencies, approximately half of the sample do not value their incorporation into public health practice. When we operationalized respondents' attitudes as the linear combination of their scores on beliefs and values questions, the sample's overall attitude was not very positive $($ mean $=53.2 \pm 20.7$, median $=54.0$; the theoretic midpoint of the scale $=59.5$ [range: $7-112$ ], with a higher score indicating more positive attitudes).

Given these lukewarm attitudes, it was not surprising to observe the sample as only marginally aware of the professional efforts to adopt genetics/genomics. Although respondents knew about the incorporation of "genetics" as a factor within the revised PRECEDE-PROCEED model, they were uninformed that organizations such as the CDC, Institute of Medicine, and NCHPEG have called for public health educators to engage in genomics-related research and practice. This finding, however, is not unique: a study of North Carolina public health nurses also revealed this group's nonfamiliarity with the CDC's genomic competencies. ${ }^{25}$
Findings also exposed a nontrivial knowledge deficiency (regarding genomics) within our sample. Because respondents with a higher level of genomics knowledge may have self-selected to take part in this study, given the survey's topic, public health educators' genomic knowledge may, in fact, be weaker than what we documented. The simplest and most immediate explanation for such gap is that the majority of training programs in health education and public health neither include genetics or genomics in their curriculum nor require course offerings in these topics for accreditation purposes. ${ }^{31-33}$

We also observed that respondents fared better in the "applied" knowledge questions than in the "basic" ones. Because public health education is an applied professional field, it makes sense that basic genomics may not be valued as highly as applied genomics. Yet, according to the Diffusion of Innovations Theory, "it is usually possible to adopt an innovation [PHG] without principles-knowledge [basic knowledge], but the danger of misusing a new idea is greater and discontinuance may result." To avoid public health educators misrepresenting genomic information to the public and, therefore, hindering the practice of genomics-related health promotion, training in essential genomics concepts and methods for public health educators should be carefully considered, and a "push" for incorporating genomic competencies without basic knowledge should be judiciously avoided.

In fact, in our sample (as in other studies of health care professionals), exposure to genetics/genomics or PHG training ${ }^{28,34}$ (and higher levels of education ${ }^{35}$ ) were associated with better genomic knowledge and awareness. Moreover, respondents with CHES certification were more aware of efforts made in health promotion regarding PHG, most likely because of the need to maintain themselves up-to-date for certification purposes. Our ability to document a significant association between PHG training and knowledge/awareness reinforces the feasibility of advocating for, and developing, CE efforts for the public health workforce. ${ }^{36}$ In addition to $\mathrm{CE}$, health promotion programs nationwide should consider the addition of courses focusing on PHG and its applications in health promotion practice. Given that integrating genomic components into community-based genomic education programs was the most valued competency among the public health educators in our sample, focusing on this skill as a starting point for courses and CE in this area may engender better acceptance and less resistance to the topic.

Last, our findings regarding associations among socioeconomic factors, attitudes, and basic \& applied genomic knowledge raise one further issue of interest. Albeit nonwhite survey respondents exhibited less basic genomic knowledge than whites, it was noteworthy that nonwhites had higher awareness regarding, and more favorable attitudes toward, the CDC genomic competencies. Despite research findings indicating that some minority groups' attitudes toward genetics/genomics are negative, ${ }^{37,38}$ our results are consistent with Singer et al.'s study, ${ }^{39}$ indicating that ethnic minorities had more positive attitudes toward using genetic testing than whites, even though minorities had less knowledge regarding testing. Laskey et al..$^{22}$ also found that ethnic minority premed students 
had positive attitudes toward using genetic testing for disease prevention and interventions. Ethnic diversity in attitudes toward PHG may, in fact, carry positive outcomes for PHG. Because public health educators often serve as linkage agents between health care systems and their own communities, positive attitudes held by minority-group professionals may encourage ethnic minorities to accept genomics-related health promotion and intervention programs in the future, further dispelling the myth that select groups view genetic developments in science suspiciously. ${ }^{40}$

\section{Study limitations}

Researchers and practitioners should consider three important limitations of this study before applying its findings. Although the survey assessed public health educators' attitudes, awareness, and knowledge related to PHG, the inability to generalize, because of potential sample bias, is its major drawback. Four factors may have contributed to sample bias. First, because of lack of information regarding the "true" population of health educators in the United States, we had to survey members of major health education professional organizations. Yet, not every health educator in the United States belongs to these selected organizations, and many belong to more than one professional association. Second, a potential self-selection bias may have occurred, because public health educators completing the survey may have held stronger beliefs about their role in PHG, may have had more genomic knowledge, or simply may have shown greater interest in this emerging topic. Third, because current research indicates that, for health professionals, web-based surveys can be an alternative to mail and telephone surveys, ${ }^{41}$ we used this nontraditional survey approach (webbased) to obtain more honest responses and recruit more participants. Yet, this could have resulted in nonresponse bias because of respondents' inability or unwillingness to complete the survey in this format. ${ }^{42}$ Because of the anonymity of the survey, we could not evaluate whether respondents and nonrespondents differed. A fourth source of bias may have been the forwarding of our survey to other public health educators by original recipients. Nevertheless, with the large sample we obtained $(n=1607)$, this may not have significantly affected our results.

Another limitation is that only a small amount of the variance in genomic knowledge and attitudes $(5 \%-11 \%)$ was accounted for by the socioeconomic factors we measured. Other factors, such as perceived compatibility between genomic principles and health educators' professional/personal role and health educators' exposure to various mass media channels (according to the Diffusion of Innovations Theory ${ }^{9}$ ), may also impact knowledge and attitudes. The purpose of this study, however, was not to search for a model to explain genomic knowledge, awareness, and attitudes. Rather, we were interested in exploring their associations as a first step in understanding public health educators' views of PHG.

A final constraint regarded the survey design used: Because the survey engine does not allow, in anonymous surveys, con- trolling for repeated responses from a single participant, it was possible for respondents to answer the survey more than once. However, because the questionnaire was long and focused on a novel topic, the odds that public health educators in our study took the survey twice are small. Research conducted on this issue, focusing on mailed surveys, has revealed the problem to be rather small in size (e.g., Summers and Price's ${ }^{43}$ survey of a national sample of health educators found the rate of double responses to their mailed questionnaire to be $<1 \%$ ). In our study, we operated under the assumption that the duplication of responses would not represent a major concern.

\section{ACKNOWLEDGMENTS}

This research was supported through various sources: Texas A\&M University's Program to Enhance Scholarly and Creative Activities Grant to Patricia Goodson, Graduate Student Research Grants from the Department of Health and Kinesiology at Texas A\&M University, the American Association of Health Education/Will Rogers Institute Fellowship, and the Society of Behavioral Medicine's Distinguished Student Award (Excellence in Research) to Lei-Shih Chen.

\section{References}

1. Centers for Disease Control and Prevention. Genomics for public health practitioners, 2004. Available at: http://www.cdc.gov. Accessed May 3, 2007.

2. Khoury MJ, Burke W, Thomson EJ. Genetics and public health in the 21st century. New York: Oxford University Press, 2000.

3. Lloyd-Puryear MA, Kyler P, Weissman G. The engagement of consumers in genetics education: lessons learned. In: Knoppers BM, editor. Populations and genetics: legal and socio-ethical perspectives. The Netherlands: Brill Academic Publishers 2003: 217-230.

4. Wang C, Bowen DJ, Kardia SL. Research and practice opportunities at the intersection of health education, health behavior, and genomics. Health Educ Behav 2005;32 (5):686-701.

5. Chen L, Goodson P. Entering the public health genomics era: why must health educators develop genomic competencies? Am J Health Educ 2007;38 (3):158-166.

6. Institute of Medicine. Who will keep the public healthy? Washington, DC: National Academics Press, 2003.

7. Centers for Disease Control and Prevention. Genomic competencies for the public health workforce, 2001. Available at: http://www.cdc.gov. Accessed April 3, 2007.

8. National Coalition for Health Professional Education in Genetics. Core competencies in genetics essential for all health care professionals, 2005. Available at: http:// www.nchpeg.org/. Accessed April 3, 2007.

9. Rogers EM. Diffusion of innovations, 5th ed. New York: Free Press, 2003.

10. Dillman DA. Mail and Internet surveys: the tailored design method. New York: John Wiley \& Sons, 2002.

11. Bankhead C, Emery J, Qureshi N, Campbell H, et al. New developments in geneticsknowledge, attitudes and information needs of practice nurses. Fam Pract 2001;18 (5):475-486

12. Henneman L, Timmermans DR van der Wal G. Public experiences, knowledge and expectations about medical genetics and the use of genetic information. Community Genet 2004;7 (1):33-43.

13. Buhi ER, Goodson P, Neilands T. Out of sight, not out of mind: strategies for handling missing data in health behavior research. Am J Health Behav. In press.

14. Brace N, Kemp R, Snelgar R. SPSS for psychologists, 3rd ed. Mahwah, NJ: Lawrence Erlbaum Associates, 2006.

15. Green LW, Kreuter MW. Health program planning: an educational and ecological approach, 4th ed. New York: McGraw-Hill, 2005.

16. Escher M, Sappino AP. Primary care physicians' knowledge and attitudes towards genetic testing for breast-ovarian cancer predisposition. Ann Oncol 2000;11 (9): 1131-1135.

17. Metcalfe S, Hurworth R, Newstead J, Robins R. Needs assessment study of genetics education for general practitioners in Australia. Genet Med 2002;4 (2):71-77.

18. Kim MY. The nurses' knowledge and perception of their role in genetics. Taehan Kanho Hakhoe Chi 2003;33 (8):1083-1092. 
19. van Langen IM, Birnie E, Schuurman E, Tan HL, et al. Preferences of cardiologists and clinical geneticists for the future organization of genetic care in hypertrophic cardiomyopathy: a survey. Clin Genet 2005;68 (4):360-368.

20. van Langen IM, Birnie E, Leschot NJ, Bonsel GJ, et al. Genetic knowledge and counselling skills of Dutch cardiologists: sufficient for the genomics era? Eur Heart $J$ 2003;24 (6):560-566.

21. Wonkam A, Njamnshi AK, Angwafo FF. Knowledge and attitudes concerning medical genetics amongst physicians and medical students in Cameroon (sub-Saharan Africa). Genet Med 2006;8 (6):331-338.

22. Laskey SL, Williams J, Pierre-Louis J O'Riordan M, et al. Attitudes of African American premedical students toward genetic testing and screening. Genet Med 2003;5 (1):49-54.

23. Baars MJ, Henneman L, Ten Kate LP. Deficiency of knowledge of genetics and genetic tests among general practitioners, gynecologists, and pediatricians: a global problem. Genet Med 2005;7 (9):605-610.

24. Baars MJ, Scherpbier AJ, Schuwirth LW, Henneman L, et al. Deficient knowledge of genetics relevant for daily practice among medical students nearing graduation. Genet Med 2005;7 (5):295-301.

25. Irwin DE, Millikan RC, Stevens R, Roche MI, et al. Genomics and public health practice: a survey of nurses in local health departments in North Carolina. J Public Health Manag Pract 2004;10 (6):539-544.

26. Peterson SK, Rieger PT, Marani SKdeMoor C, et al. Oncology nurses' knowledge, practice, and educational needs regarding cancer genetics. Am J Med Genet 2001;98 (1):3-12.

27. Kulkarni AS, Sansgiry SS. The human genome project-pharmacogenomics: how will it affect the role of pharmacists? J Manag Care Pharm 2002;8 (6):525.

28. Hofman KJ, Tambor ES, Chase GA, Geller G, et al. Physicians' knowledge of genetics and genetic tests. Acad Med 1993;68 (8):625-632.

29. Suther SG, Goodson P. Texas physicians' perceptions of genomic medicine as an innovation. Clin Genet 2004;65 (5):368-377.

30. Clayton EW. Ethical, legal, and social implications of genomic medicine. $N$ Engl J Med 2003;349 (6):562-569.

31. Woodhouse LD, Auld ME, Livingood WC, Mulligan LA. Survey of accredited Master of Public Health (MPH) programs with health education concentrations: a re- source for strengthening the public health workforce. Health Promot Pract 2006;7: 258-265.

32. Council on Education for Public Health. Accreditation criteria schools of public health. Amended June 2005. Available at: http://www.ceph.org. Accessed April 3, 2007.

33. Council on Education for Public Health. Accreditation criteria public health programs. Amended June 2005. Available at: http://www.ceph.org. Accessed April 3, 2007.

34. Wilkins-Haug L, Hill LD, Power ML, Holzman GB, et al. Gynecologists' training, knowledge, and experiences in genetics: a survey. Obstet Gynecol 2000;95 (3):421424.

35. Sansgiry SS, Kulkarni AS. The human genome project: assessing confidence in knowledge and training requirements for community pharmacists. Am J Pharm Educ 2003;67 (2):1-10.

36. Guttmacher AE, Porteous ME, McInerney JD. Educating health-care professionals about genetics and genomics. Nat Rev Genet 2007;8 (2):151-157.

37. Peters N, Rose A, Armstrong K. The association between race and attitudes about predictive genetic testing. Cancer Epidemiol Biomarkers Prev 2004;13 (3):361-365.

38. Sheldon JP, Epstein Jayaratne T, Feldbaum MB, DiNardo CD, et al. Applications and implications of advances in human genetics: perspectives from a group of Black Americans. Community Genet 2007;10 (2):82-92.

39. Singer E, Antonucci T, Van Hoewyk, J. Racial and ethnic variations in knowledge and attitudes about genetic testing. Genet Test 2004;8 (1):31-43.

40. Fouad MN, Partridge E, Wynn T, Green BL, et al. Statewide Tuskegee Alliance for clinical trials. A community coalition to enhance minority participation in medical research. Cancer 2001;91 (1 Suppl):237 -241.

41. Braithwaite D, Emery J, De Lusignan, S, Sutton S. Using the Internet to conduct surveys of health professionals: a valid alternative? Fam Pract 2003;20 (5):545551.

42. Alvarez RM, VanBeselaere C. Web-based surveys. In: Kempf-Leonard K, editor. Encyclopedia of social measurement. London: Academic, 2005:955-962.

43. Summers J, Price JH. Increasing return rates to a mail survey among health educators. Psychol Rep 1997;81 (2):551-554. 